\title{
Carbon Dioxide Euthanasia
}

National Cancer Institute

\section{Source}

National Cancer Institute. Carbon Dioxide Euthanasia. NCI Thesaurus. Code C90369.

A method of euthanization whereby a subject inhales carbon dioxide until death occurs. 